\title{
Laboreal
}

Volume $16 \mathrm{~N}^{\circ} 1 \mid 2020$

Quando o trabalho real é tabu

\section{A psicologia do trabalho : um apanhado}

Psicología del trabajo : una descripción general

La Psychologie du travail: un aperçu

The Work psychology: an Overview

\section{Jacques Leplat}

Tradutor. João Viana Jorge

\section{OpenEdition}

\section{Journals}

\section{Edição electrónica}

URL: http://journals.openedition.org/laboreal/16166

DOI: $10.4000 /$ laboreal. 16166

ISSN: 1646-5237

\section{Editora}

Universidade do Porto

\section{Refêrencia eletrónica}

Jacques Leplat, «A psicologia do trabalho: um apanhado », Laboreal [Online], Volume 16 N01 | 2020 posto online no dia 01 julho 2020, consultado o 08 julho 2020. URL : http://journals.openedition.org/ laboreal/16166 ; DOI : https://doi.org/10.4000/laboreal.16166

Este documento foi criado de forma automática no dia 8 julho 2020.

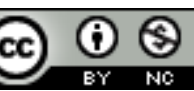

Laboreal está licenciado com uma Licença Creative Commons - Atribuição-NãoComercial 4.0 Internacional. 


\section{A psicologia do trabalho : um apanhado}

Psicología del trabajo : una descripción general

La Psychologie du travail: un aperçu

The Work psychology: an Overview

Jacques Leplat

Tradução : João Viana Jorge

\section{REFERÊNCIA}

Texto original [1] : Leplat, J. (1980). La psychologie du travail: un aperçu. Bulletin de Psychologie. Tome XXXIII, n² 344, 195-200.

\section{NOTA DO EDITOR}

Tradução: João Viana Jorge - joaojorg@gmail.com

1 Este apanhado pretenderá fazer sobressair alguns traços importantes da psicologia do trabalho. Não pretende substituir-se aos textos mais completos consagrados à apresentação da disciplina que se encontram nomeadamente nos manuais (tomo I do Traité de Psychologie Appliquée, por exemplo). Poderá ajudar o leitor a se situar e a interrogar os textos que se seguirão.

\section{Delimitação do campo}

2 A psicologia do trabalho refere-se a uma divisão da psicologia em termos de objeto de estudo : entre as outras classes desta divisão figuram por exemplo a psicologia escolar, a psicologia do desporto, a psicologia da arte. A definição do campo da psicologia do 
trabalho remete-nos para a de trabalho. Para o psicólogo o trabalho é essencialmente "uma atividade necessária ao desempenho de uma tarefa " (Robert). Esta atividade complexa e multiforme foi objeto de numerosas definições que fazem sobressair diversos aspetos :

- é especificamente humana (Leontiev, 1976) ;

- é adquirida por aprendizagem (Ombredane \& Faverge, 1955) ;

- põe em jogo “ dois elementos interdependentes : um deles é o uso e fabrico de utensílios (...) e um segundo, o de que o trabalho se efetua em condições de atividade comum, coleciva » (Leontiev, 1976, p. 67);

- tem uma característica constrangedora (Ombredane \& Faverge, 1955, Wallon, 1946). “O único critério comum às atividades assim denominadas (trabalho) é um elemento de compulsão (constrangimento, obrigação, disciplina, etc....) que pode ser de origem interna ou externa » (Friedman, 1976).

3 Não esqueceremos que o termo “trabalho" é polissémico. Designa também frequentemente o fruto da atividade, aquilo a que ela se aplica e torna-se mais ou menos sinónimo de obra ou de tarefa. É o sentido que se encontra em expressões como “ fazer o seu trabalho » $\mathrm{e}$ " sistema homem - trabalho » ou " unidade de trabalho ».

4 Das primeiras definições se deduz a ideia de que o estudo psicológico do trabalho pode fazer-se em relação a quadros de referência variados.

5 O trabalhador interage primeiro com os seus instrumentos de trabalho e o seu meio ambiente técnico imediato. Faz também parte dum sistema sócio técnico englobando o primeiro e ele próprio parte de sistemas mais vastos até às instituições definidoras, por exemplo, de certas regras do trabalho (legislação diversa sobre os tempos de trabalho, sobre a segurança, etc.). O trabalhador está também inserido em organizações (profissionais, sindicais) e numa sociedade constituindo outras tantas fontes de determinantes adequadas à explicação da sua conduta. Ter-se-ia aí uma base possível para um recorte do campo.

6 Os estudos e pesquisas referentes ao domínio do trabalho começaram a ser repertoriados sob o nome muito geral de psicologia aplicada ou de psicotécnica. A seguir o domínio diferenciou-se e Myers propôs em 1925 o nome de psicologia industrial. Esta designação ainda amplamente expandida é, todavia, limitativa dado que o trabalho não é só industrial como também agrícola, comercial, administrativo, etc. $O$ termo de psicologia do trabalho, mais geral, é, portanto, preferível para designar o conjunto do domínio. Foi proposto por Walther em 1926 mas obteve pouco sucesso até um período recente em que parece ter ganho terreno.

7 Podem considerar-se como sectores da psicologia do trabalho os que forem definidos a partir dos tipos de intervenção : psicologia ergonómica (às vezes dita da engenharia), psicologia da formação (ou psicopedagogia profissional), psicologia profissional.

8 A psicologia das organizações, que se interessa no seu sentido lato pelos determinantes sócio técnicos das condutas, constitui também uma parte da psicologia do trabalho. Manifesta frequentemente uma certa propensão para abarcar todo o campo da psicologia do trabalho partindo sem dúvida da ideia que, exercendo-se qualquer trabalho no seio de uma organização, o estudo da organização inclui o do trabalho. 


\section{Estruturação do campo}

9 Esta estruturação pode ser concebida a partir da psicologia ou a partir do trabalho : este segundo princípio foi aqui o escolhido e ilustra o quadro I

Quadro I: Os grandes campos da Psicologia do Trabalho

\begin{tabular}{|c|c|c|}
\hline Campos de estudos & $\begin{array}{l}\text { Campos de conhecimentos } \\
\text { psicológicos (exemplos) }\end{array}$ & $\begin{array}{l}\text { Campos de intervenção } \\
\text { (exemplos) }\end{array}$ \\
\hline $\begin{array}{cc}\text { Unidade individual } & \text { de } \\
\text { trabalho } & \\
\text {-Em relação } & \text { ao } \\
\text { trabalhador } & \\
\text {-Em relação } & \text { às } \\
\text { condições } & \text { de } \\
\text { trabalho } & \\
\text {-Características } & \\
\text { próprias } & \end{array}$ & $\begin{array}{l}\text { Diferenças individuais. } \\
\text { Aprendizagem. } \\
\text { Perceção sensório } \\
\text { motricidade } \\
\text { Processos cognitivos. } \\
\text { Conjunto dos precedentes. }\end{array}$ & $\begin{array}{l}\text { Recrutamento. Formação. } \\
\text { Afetação } \\
\text { Ergonomia elementar } \\
\text { Avaliação dos postos. } \\
\text { Segurança. }\end{array}$ \\
\hline $\begin{array}{l}\text { Conjunto de unidades } \\
\text {-Em relação ao grupo } \\
\text {-Em relação às } \\
\text { condiçốes } \\
\text { trabalho } \\
\text {-Características } \\
\text { próprias }\end{array}$ & $\begin{array}{l}\text { Comunicação. Trabalho de } \\
\text { grupo. } \\
\text { Estrutura da tarefa/estrutura } \\
\text { do grupo } \\
\text { Conjunto dos precedentes. }\end{array}$ & $\begin{array}{l}\text { Melhoramento das relações } \\
\text { humanas, } \\
\text { das comunicações, do clima. } \\
\text { Ergonomia dos sistemas. } \\
\text { Organização do trabalho. } \\
\text { Gestão. }\end{array}$ \\
\hline $\begin{array}{lr}\text { Dimensão histórica } & \\
\text {-Evolução } & \text { dos } \\
\text { trabalhadores } & \\
\text {-Evolução } & \text { das } \\
\text { condições } & \text { de } \\
\text { trabalho } & \\
\text {-evolução } & \text { das } \\
\text { unidades de trabalho }\end{array}$ & $\begin{array}{l}\text { Mobilidade social e } \\
\text { profissional. } \\
\text { Envelhecimento. } \\
\text { Mudanças. Problemas } \\
\text { interculturais. } \\
\text { Conjunto dos precedentes. }\end{array}$ & $\begin{array}{l}\text { Gestão das carreiras. } \\
\text { Ergonomia de conceção. } \\
\text { Planificação do emprego. }\end{array}$ \\
\hline
\end{tabular}

Quadro I: Os grandes campos da Psicologia do Trabalho

Os campos de estudo distinguem-se pela extensão e por tomar em consideração a dimensão histórica. Considerar-se-á suficiente comentar aqui a primeira parte distinguida. No que diz respeito aos campos de estudo ( $1^{\mathrm{a}}$ coluna), ao nível da unidade de trabalho, serão tomados em consideração as situações de trabalho individuais quer se considere uma das funções confiadas ao trabalhador e por ele executadas, quer se considere o conjunto dessas mesmas funções. É assim que se poderão estudar as atividades de classificação ou de dactilografia de uma secretária ou ainda a organização do conjunto das suas atividades. A unidade de trabalho ( $2^{\mathrm{a}}$ coluna) pode ser analisada sob o ângulo comparativo ou diferencial : são então tomadas em conta as características dos trabalhadores relativas à sua tarefa : (capacidade, nível de formação, experiência, interesse, personalidade, etc.). As metodologias encontram aqui fundamento na análise de grupos de sujeitos.

11 A unidade de trabalho é também analisável por ligação às condições de trabalho das quais se estudarão os efeitos na organização da atividade. Por condições de trabalho entender-se-ão aqui todas as condições exteriores aos trabalhadores - instruções, regras de trabalho, condições tecnológicas, objetos e terminologia técnica, etc. - que são tidas em conta na conduta. Determinar-se-á o papel dessas condições fazendo-as variar nomeadamente segundo os métodos de tipo experimental. 

lhe a estrutura e o funcionamento. Poder-se-á assim classificar a unidade em relação com tipologias variadas. Por exemplo poder-se-ão ordenar os postos de secretárias segundo as competências exigidas, os tipos de formação e os dispositivos técnicos postos à sua disposição. conhecimentos da disciplina da qual algumas categorias foram mencionadas ( $2^{\mathrm{a}}$ coluna) a título de exemplo. Correspondem aos recortes correntemente evocados e bem repertoriados. Não são, bem entendido, independentes: por exemplo, as diferenças individuais podem incidir em aspetos percetivos. São ainda menos exaustivos. Aqui a sua única virtude é a de servir de ilustração.

Enfim uma terceira coluna menciona os tipos de intervenção suscetíveis de explorar os conhecimentos precedentes. Assim um estudo das características dos condutores de pesados num determinado contexto poderá ser explorado para melhorar o recrutamento ou definir melhores programas de formação. Mas a elaboração de um procedimento de recrutamento e de formação fará também apelo a conhecimentos e competências extra psicológicas (de gestão, pedagógicas, tecnológicas, etc.).

Os campos de estudo podem ser também constituídos por conjuntos de unidades mais ou menos extensas (equipa, serviço, atelier, por exemplo). Fala-se então, frequentemente, de sistemas sócio técnicos para assinalar que se trata de um conjunto de trabalhadores e de condições técnicas (instalações, material, regras de trabalho, etc.) em interação. Poderiam ainda ser examinadas sob os três aspetos antes mencionados.

Enfim, poder-se-iam considerar todas as unidades precedentes sob o ponto de vista histórico e estudá-los através da sua evolução.

0 recorte apresentado no quadro I poderia ser facilmente afinado. As categorias que define não são independentes e representam de facto pontos de vista sobre uma mesma complexa realidade. Qualquer conduta pode ser referida a cada um dos campos definidos, mas estes serão mais ou menos pertinentes conforme os objetivos do estudo.

\section{Psicologia do trabalho e psicologia aplicada}

A psicologia do trabalho é comummente arrumada na psicologia aplicada e para muitos não será senão uma psicologia aplicada. Se por isso se entender que é orientada essencialmente para a solução de problemas práticos teremos uma conceção errónea e truncada da psicologia do trabalho. Com efeito o que define então a aplicação é a pesquisa de soluções visando a satisfação de um certo número de critérios fixados (implícita ou explicitamente) pelas pessoas que solicitam o estudo. No domínio do trabalho os critérios são de vários tipos : distinguem-se frequentemente os que dizem respeito muito diretamente ao trabalhador (segurança, satisfação, saúde, etc....) e os que dizem respeito ao sistema sócio técnico (quantidade e qualidade da produção, fiabilidade, etc....).

Qualquer aplicação implica a tomada em consideração de alguns desses critérios de maneira mais ou menos explícita. Isso torna-se evidente nos estudos de validação de alguma seriedade. Encontrar-se-iam exemplos formalizados em Ombredane e Faverge (1955) e em Cronbach e Gleser (1957) a propósito de recrutamento e muitos outros em diversos domínios. A tradução destes critérios numa escala monetária permite tratá-los 
frequentemente em conjunto e coloca muito claramente o problema dos respetivos pesos a serem-lhes atribuídos. Não se pode escapar a este problema na aplicação e a sua solução põe inevitavelmente em jogo as relações sociais de força. Com efeito os atores sociais não atribuem o mesmo peso relativo a esses critérios e a solução de compromisso à qual chegam é a expressão dessas relações. 0 psicólogo pode dizer (no melhor dos casos) que numa dada situação tal solução terá tais consequências (uma formação com tal categoria de sujeitos, tal método, tal duração, alcançará tal tipo de competência), com uma dada aproximação.

A escolha da solução não é de natureza psicológica visto que vai fazer intervir o custo da implementação da formação, a dificuldade do recrutamento, o benefício calculado do resultado para o indivíduo e para a organização, etc. A avaliação da importância relativa desses elementos, indispensável para a escolha de uma solução, não é de natureza psicológica.

o psicólogo, graças aos seus conhecimentos, poderá esclarecer o debate social, mostrar consequências das escolhas para os trabalhadores e para o sistema, mas não está qualificado para definir a boa solução.

$\mathrm{Na}$ falta de tomar claramente consciência desses problemas certos psicólogos imputam à sua disciplina decisões que dela não relevam. Reticências por vezes manifestadas a respeito da nossa especialidade têm frequentemente essa origem. Para mostrar quão vigilante se deve ser a este respeito referir-se-á a obra de Walther (1926). No prefácio que nela redigiu, Claparède, de resto um bom psicólogo, permitiu-se escrever certo número de reflexões das quais o mínimo que pode dizer-se é que se prestam a um sorriso. "Mais depressa talvez do que pensava, o Sr. Walther obtém (...) resultados maravilhosos : é que a maneira de trabalhar de operários e contramestres deixados por sua conta é ainda mais irracional do que se supunha!» ... “O que nos interessa é sobretudo a relação entre o rendimento antes da organização do trabalho e o rendimento após a intervenção do nosso perito psicólogo ». Segue-se um quadro " antes - depois » que Claparède comenta : “Como se vê o rendimento é muito frequentemente duplicado ou triplicado às vezes mesmo quintuplicado, até mesmo sextuplicado! Estes números (...) mostram melhor que longas frases o grande partido que o Sr. Walther soube tirar da organização científica do trabalho ». Enfim, o Sr. Walther é louvado por ter sabido durante uma prática de cinco anos "alcançar a harmonia entre patrões e operários. Capaz de se colocar sob pontos de vista de uns e outros, aparentemente opostos, compreendeu que um trabalho digno desse nome não podia senão implicar uma estreita solidariedade dos seus interesses, por assim dizer divergentes, e obedecer em simultâneo às exigências da natureza humana e às da produção. 0 princípio da racionalização do trabalho refundido pelo calor de uma profunda simpatia pelo trabalhador, Taylor corrigido pela psicologia, - tal foi a obra benfazeja tanto quanto habilidosa do Sr. Léon Walther» ( $\mathrm{p}$. XII a XIV). Para escapar aos procedimentos habituais (e em geral erróneos) manifestos nas precedentes citações e não fornecer uma vestimenta científica a práticas que visam outras finalidades, é preciso o esforço de distinguir o que releva da psicologia e o que lhe é estranho. Com esta finalidade o psicólogo do trabalho deve proceder a um diagnóstico cuidadoso dos problemas que lhe propõem estudar a fim de não desposar sem qualquer crítica a problemática de quem solicita os seus serviços. 


\section{Psicologia do trabalho e psicologia}

23 As relações da psicologia do trabalho com as aplicações dela derivadas são as mesmas que as da psicologia com a psicologia aplicada e poder-se-ia muito bem falar de psicologia do trabalho fundamental e psicologia do trabalho aplicada. A psicologia do trabalho (fundamental) é parte integrante da psicologia. Como ela, visa determinar as condições de aquisição e de execução de condutas e as suas consequências nas características do sujeito. As condutas pelas quais se interessa podem dar lugar a pesquisas teóricas como pode acontecer com qualquer outro ramo. 0 psicólogo que estuda a maneira como um operador vigia e corrige o funcionamento de uma instalação a partir de um quadro de controlo à distância pode fazê-lo com os mesmos quadros teóricos e os mesmos métodos que o psicólogo que estuda em laboratório a resolução de um puzzle ou o jogo da torre de Hanói.

Pode sempre tentar-se assinalar o que dá especificidade à psicologia do trabalho no interior da psicologia. Contentar-nos-emos com esboçar alguns traços. As condutas pelas quais se interessam os psicólogos do trabalho são relacionadas com condições que não são por ele construídas, mas que se lhe impõem como aliás se impõem aos trabalhadores. Essas condutas, como já vimos, relevam de múltiplos determinantes dos quais será sempre útil avaliar, pelo menos aproximadamente, o papel relativo ao começo de um estudo e daí a importância frequentemente sublinhada da análise do trabalho. O psicólogo do trabalho terá sempre a preocupação de tratar um verdadeiro problema no sentido em que o modelo de situação que propõe dá conta de boa parte da variação do ou dos critérios que terá escolhido para caracterizar o trabalho. É preciso também não esquecer que as condutas estudadas se exercem em condições das quais muitas serão sempre dificilmente se não impossíveis de reproduzir artificialmente (condições socioeconómicas, organizacionais, etc.).

Assim, as situações de trabalho apresentam um certo número de características que não sendo completamente originais são todavia pouco abordadas na pesquisa psicológica tradicional : citar-se-ão alguns exemplos típicos.

Os trabalhadores podem exercer a sua atividade numa mesma tarefa durante períodos muito longos. Enquanto no laboratório uma aprendizagem dura no máximo umas horas, na empresa o exercício de uma mesma tarefa pode prolongar-se por semanas, meses, até mesmo anos. Os mecanismos de regulação da atividade podem ser profundamente transformados: por isso as habilidades e automatismos sensório motores e mentais vão ganhar uma grande importância. A sua elaboração, funcionamento, a sua eventual degradação vai colocar problemas importantes que escapam com frequência à psicologia de laboratório.

Outro exemplo de problemas originais colocados por situações de trabalho é o do papel desempenhado pelos fatores inerentes à organização. 0 meio social de trabalho e mais amplamente ainda o meio sócio técnico condicionam as atitudes, as motivações e as condutas do trabalhador ou mesmo certos traços da sua personalidade segundo mecanismos que são ainda insuficientemente conhecidos. Há aí um vasto campo aberto a uma pesquisa psicológica fundamental.

Evoquemos brevemente alguns outros casos que mereceriam investigações aprofundadas: as tarefas em tempo partilhado nas quais os operadores têm de organizar as suas atividades em função de solicitações variadas e mais ou menos 
imprevistas quanto ao momento em que surgem, as atividades levadas a cabo sob constrangimentos temporais estritos, os efeitos da idade, particularmente o envelhecimento profissional, etc.

A psicologia do trabalho coloca com agudeza e em diversos aspetos o problema do reducionismo. Já foi mencionado que qualquer situação de trabalho era analisável em relação a múltiplos quadros de referência: psicofisiológicos, psicológicos, psicossociológicos, podendo facilmente cada uma destas grandes divisões ser detalhada. Ora qualquer pesquisa conduz necessariamente à escolha de um quadro de referência particular e a negligenciar por isso mesmo todas as outras com todas as consequências que isso arrasta. Assim, se se estudam os automatismos nos trabalhadores em cadeia, os grupos de referência que tenderiam a ser escolhidos para ensaiar as hipóteses formuladas sobre este tema não serão os mesmos que se definiriam se o interesse nesse mesmo trabalho fosse o problema da motivação dos trabalhadores ou o papel da origem desses trabalhadores (nacionalidade, nível cultural, idade, etc.) ou o da organização na qual se inserem. $O$ efeito desta redução, inerente a qualquer estudo de psicologia, será sempre uma preocupação para a psicologia do trabalho. Será uma das funções importantes da análise psicológica do trabalho, avaliá-lo. O diagnóstico ao qual conduz tentará determinar o papel que podem desempenhar na conduta os diferentes sistemas de variáveis nas quais se insere.

O investigador vai reencontrar este problema logo que pretenda transpor para o laboratório um aspeto da situação para lhe estudar os mecanismos com maior precisão. É então necessariamente levado a examinar as relações do seu modelo da situação com a própria situação e isto sob dois ângulos : a situação experimental é mesmo o modelo do aspeto da situação pela qual se interessa, e qual fração das variações da conduta na situação de base é explicada pelo mecanismo estudado na situação modelo. Estes problemas são frequentemente evocados em psicologia do trabalho sob o título de simulação ou, no sentido mais lato, de relações “terreno/laboratório » (Leplat, 1973, 1978).

\section{A evolução da psicologia do trabalho}

31 Terminará este apanhado apresentando alguns traços da evolução da psicologia do trabalho no decurso destes últimos anos. Alguns deles podem ser recolhidos concretamente do exame comparativo do conteúdo dos manuais atuais e do de outros de uns anos atrás. Bom exemplo disso é-nos fornecido pelas três edições sucessivas do manual de Tiffin. O tratado de Dunnette (1976) sugere outros na sua Introdução. O exame das revistas é igualmente significativo.

Diferenciação e especialização no interior da psicologia do trabalho

Como assinalamos num capítulo do Traité de Psychologie appliquée (1972) a evolução não se assinala tanto pela natureza de novos campos como por uma importância menos desigual atribuída a cada um dos existentes. Assim, os estudos diferenciais conduzidos na base de testes que constituíam o essencial dos antigos manuais veem reduzir-se o seu espaço enquanto o da psicologia ergonómica e o da psicologia das organizações cresceu muito. As comparações tornaram-se aliás frequentemente difíceis em virtude da especialização das obras e das revistas. A psicologia ergonómica e a psicologia das organizações para não citar senão estes dois ramos particularmente ativos criaram os 
seus próprios manuais e as suas revistas (Ergonomics, Human Factors, Organizational Behavior and Human performance, etc.).

Em França a evolução de revistas como o Bulletin du CERP e o Travail Humain mostra bem o "reequilíbrio" dos diferentes ramos da psicologia do trabalho. A evolução parece mais lenta ao nível das práticas da psicologia mas faltam dados estatísticos precisos para essa avaliação. A última parte deste número especial fornecerá algumas indicações sobre esse ponto.

\section{citar a melhoria da formação de base dos psicólogos, o desenvolvimento (embora} tímido, lamentavelmente) do ensino da psicologia do trabalho no meio universitário e enfim as comunicações mais numerosas entre sociedades ou secções de psicologia geral e do trabalho. Os congressos internacionais da Association de Psychologie scientifique e os da Association internationale de Psychologie apliquée mostram frequentemente que os mesmos psicólogos são suscetíveis de abordar os problemas do trabalho sob o prisma da prática no caso dos primeiros ou sob o prisma da teoria no caso dos segundos. No capítulo introdutório do seu recente tratado, Dunnette (1976) confirma aquelas asserções: "As mudanças no campo da psicologia industrial e das organizações no último quarto de século aparecem de modo surpreendente na comparação de dois manuais. O manual de 1950 (Fryer \& Henry) era quase exclusivamente um manual de práticas pondo a tónica nas técnicas e nas aplicações e dedicando pouca atenção à pesquisa e à metodologia da pesquisa e nenhuma atenção a qualquer teoria do comportamento individual ou da organização. Por contraste, o presente manual acentua notoriamente as estratégias e a metodologia da pesquisa, as teorias do comportamento e dá um forte relevo às características e ao impacto das forças e influências sócio psicológicas que impliquem processos de interação entre as organizações e as pessoas ...)» (p. 2-8).

Este maior espaço aberto aos fundamentos teóricos da disciplina encontra-se também no modo como são apresentadas as metodologias práticas de intervenção. Enquanto que no passado elas tinham frequentemente assumido o papel de receitas são agora cada vez mais oriundas "de conhecimentos desenvolvidos a partir de pesquisas e de 
temas » (Dunnette 1976, p. 8). As suas condições de aplicação são assim mais bem explicitadas e o seu uso é mais flexível.

\section{Diagnóstico dos problemas precedentes da intervenção}

Parece enfim que se pode discernir uma evolução na maneira como os estudos são definidos. O psicólogo, parece mais - e mais frequentemente que no passado convidado a resolver um problema do que a aplicar uma técnica ou pôr a andar uma determinada intervenção. Esta evolução é muito positiva e sem dúvida favorecida pelo alargamento das suas competências tal como pelo progresso da disciplina. Disso encontramos traços em obras recentes Laville (1976), Leplat e Cuny (1977), Duraffourg e colegas (1978).

Estando associado ao diagnóstico dos problemas o psicólogo pode escapar ao papel de técnico - no sentido de aplicador de técnicas determinadas - ao qual estava frequentemente confinado quando lhe solicitavam tipos de intervenção (recrutamento, formação, por exemplo) dos quais não tinha que avaliar a pertinência. Procedendo assim pode ter uma visão mais clara do alcance da sua ação e assegurar-se de que corresponde bem à que lhe atribui, particularmente no plano social.

\section{Conclusão}

A psicologia do trabalho tem, portanto, um desígnio teórico e um prático a distinguir e a articular ao mesmo tempo. Os autores que refletiram sobre o estatuto da disciplina sublinharam esse carácter e essa necessidade (por exemplo Rodger, 1949 ; Dubin, 1976). Os desígnios teórico e prático podem ter pesos diferentes num estudo ou numa intervenção segundo os objetivos e as condições dos mesmos. Podem também revestir ponderações diferentes conforme o papel dos psicólogos nas instituições em que exercem as suas atividades. Mas em todos os casos a interação entre os dois desígnios é essencial. A investigação, de facto dificilmente pode ignorar o alcance prático das teorias e dos modelos que ela elabora e o mesmo sucede com os aspetos psicológicos das intervenções no terreno. Do mesmo modo o praticante não pode desprezar sem inconvenientes as teorias ou pelo menos os quadros conceptuais oferecidos pela sua disciplina. Esta interação entre os dois desígnios é uma condição de progresso nos dois casos. A teoria e os modelos da psicologia ajudarão a interrogar as situações de trabalho e inversamente essas mesmas situações poderão interrogar essas teorias e esses modelos e contribuir para delimitar o seu campo de pertinência.

\section{BIBLIOGRAFIA}

Cronbach, J.L. \& Gleser, G.C. (1957). Psychological tesis and personnal decisions. University of Illinois Prese, Urbana.

Dubin, R. (1976). Theory building in applied areas (p. 1740), ln M. D. Dunette, Handbook of industrial and organizational psychology. Chicago: Rand Mac Nally College Publishing Company.

Dunette, M.D. (1976). Handbook of industrial and organizational psychology. Chicago: Rand Mac Nally College Publishing Company. 
Duraffourg, J., Guerin, F., Jankowky, F., Mascot, J.C. (1977). Analyse des activités de l'homme en situation de travail. Doc du Laboratoire de Physiologie du Travail - Ergonomie du C.N.A.M.

Friedmann, G. (1976). Ou va le travai ! humain ? Le Monde (10-1-1976).

Laville, A. (1976). L'Ergonomie. Paris: PUF.

Leplat, J. (1972). La Psychologie du travail en ergonomie (pp. 61-136). ln M. Reuchlin, Traité de Psychologie Appliquée. Paris: PUF.

Leplat, J. (1973). La méthode expérimentale en psychologie appliquée. (pp. 19-62). ln M. Reuchlin, Traité de Psychologie Appliquée. Tome II. Paris: PUF.

Leplat, J. (1978). L'équivalence des situations de laboratoire et de terrain. Le Travail Humain, 41, 2, 307-318.

Leplat, J. \& Cuny, X. (1977). Introduction à la Psychologie du Travail. Paris: PUF.

Leontiev, A. (1976). Le développement du psychisme. Paris: Editions Sociales.

Ombredane, A. \& Faverge, J.M. (1955). L'analyse du travail. Paris : PUF.

Reuchlin, M. (1971) Traité de Psychologie Appliquée. Tome 1, Les applications de la psychologie. Paris : PUF.

Rodger, A. (1949). What is industrial psychology. Occupational Psychology, XXIII, 3, 170-180.

Tiffin, J. \& Mc Cormick, E. J. (1967). Psychologie industrielle. Paris: PUF.

Wallon, H. (1946). Principes de psychologie appliquée. Paris : A. Colin.

Walther, L. (1946). La psychologie du travail. Geneve: Ed. du Mt Blanc.

\section{NOTAS}

1. NT: O Diretor da publicação Bulletin de psychologie autorizou a reprodução e tradução deste artigo de Leplat. 